UCRL-JC-105442

PREPRINT

\title{
Performance Characteristics of an Induction Linac Magnetic Pulse Compression Modulator at Multi-kilohertz Pulse Repetition Frequencies
}

\author{
S.E. Sampayan, F.W. Chambers, F.J. Deadrick, W.A. Niven, \\ C.W. Ollis, A.N. Payne, V.L. Renbarger, E.T. Scharlemann, \\ W.C. Turner, and J.A. Watson
}

This paper was prepared for submittal to the 1991 IEEE Particle Accelerator Conference May 6-9, 1991, San Francisco, CA

May, 1991

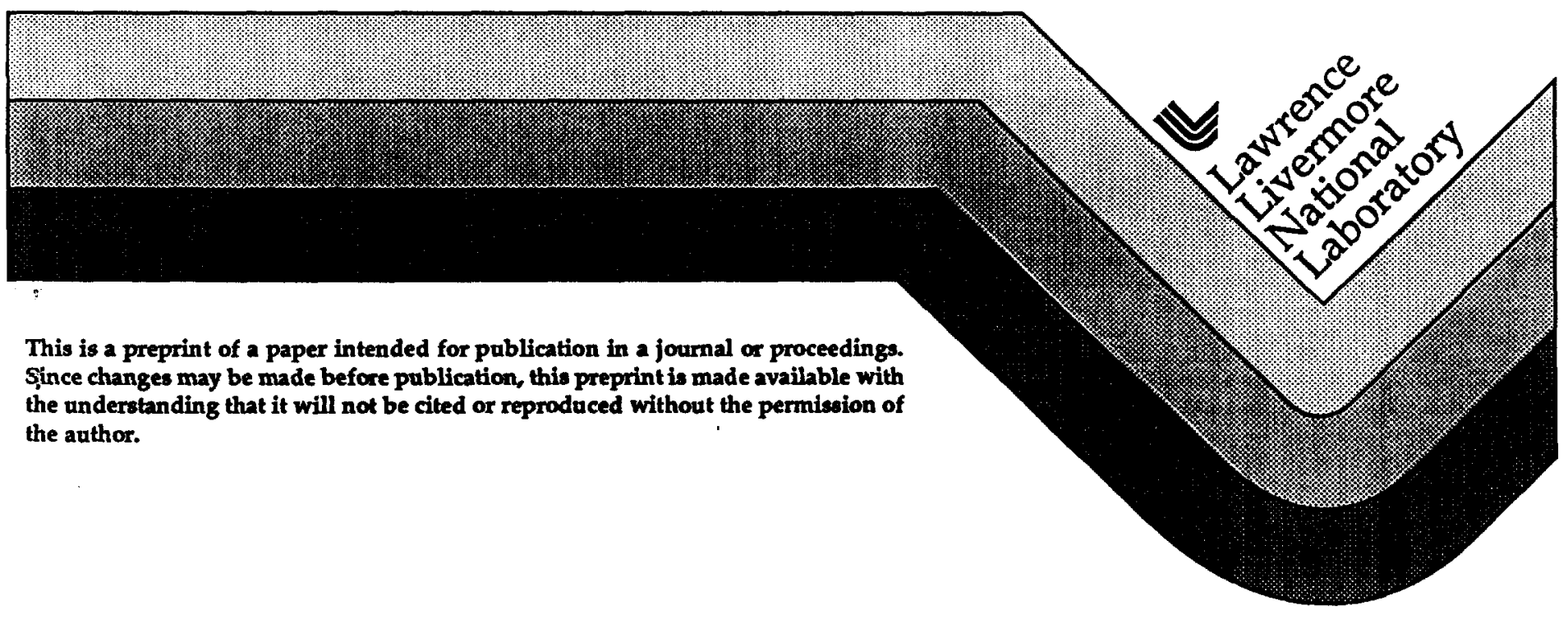




\section{DISCLAIMER}

This document was prepared as an account of work sponsored by an agency of the United States Government. Neither the United States Government nor the University of California nor any of their employees, makes any warranty, express or implied, or assumes any legal liability or responsibility for the accuracy, completeness, or usefulness of any information, apparatus, product, or process

disclosed, or represents that its use would not infringe privately owned rights. Reference herein to any specific commercial product, process, or service by trade name, trademark, manufacturer, or otherwise, does not necessarily constitute or imply its endorsement, recommendation, or favoring by the United States Government or the University of California. The views and opinions of authors expressed herein do not necessarily state or reflect those of the United States Government or the University of California, and shall not be used for advertising or product endorsement purposes. 


\title{
Performance Characteristics of an Induction Linac Magnetic Pulse Compression Modulator at Multi-kilohertz Pulse Repetition Frequencies
}

\author{
S. E. Sampayan, F. W. Chambers, F. J. Deadrick, W. A. Niven, C. W. Ollis, A. N. Payne, \\ V. L. Renbarger, E. T. Scharlemann, W. C. Tumer, and J. A. Watson \\ Lawrence Livermore National Laboratory \\ Livermore, CA 94550
}

\section{Abstract}

The ETA-II linear induction accelerator utilizes four pulse power conditioning chains. Magnetic pulse compression modulators (MAG1-Ds) form the last stage of each chain. A single power conditioning chain is used to drive the injector; the remaining three are used to drive 60 accelerator cells. Nominal parameters of the MAG1-D are an output voltage of greater than $120 \mathrm{kV}$, pulse width of $70 \mathrm{~ns}$, and an output impedance of 2 ohms. Our operations goal for ETA-II is stable high average power operation at $5 \mathrm{kHz}$ PRF.

We have begun upgrading and characterizing the power conditioning chain on our High Average Power Test Stand (HAPTS). On HAPTS, the pulse to pulse amplitude stability has been improved to less than $0.7 \%$ (one sigma) and of order 3 - 5 ns random jitter about a systematic timing variation. In this paper we describe the status of our work to achieve the desired performance level of the MAG1-D to allow high average power operation of ETA-II.

\section{Introduction}

Linear induction accelerators (LIAs) are used to produce high average power charged particle beams. These accelerators have been operated at high current (greater than $1 \mathrm{kA}$ ), moderate energy (order 10s of MeV) and at high repetition rates (order $5 \mathrm{kHz}$ ) [1-3]. Operation of the LIA depends on the time rate of change of magnetic flux through the magnetic material (typically ferrite) within the accelerator cells. The changing flux produces an acceleration gradient along the accelerator axis which imparts energy to the charged particle beam. [4].

The ETA-II accelerator, in the 60 cell configuration, is nominally a $7.5 \mathrm{MeV}, 2 \mathrm{kA}$ electron beam accelerator; $1 \mathrm{Mev}$ is imparted to the beam at the hot cathode injector, $6.5 \mathrm{MeV}$ is imparted to the beam over 60 accelerator cells. Usable pulse width typically varies between $30-50 \mathrm{~ns}$ for an energy sweep, $\mathrm{dE} / \mathrm{E}$, of about $1 \%$. Although ETA-II was designed for $5 \mathrm{kHz}$ burst operation, limitations within the power conditioning chain prevented operation at full repetition rate.

The HAPTS pulse power conditioning chain was modeled after the ETA-II power conditioning chain and is used as a test bed to upgrade ETA-II systems. HAPTS consists of a capacitor bank for burst operation, a pulse power unit (PPU) and magnetic pulse compression modulator (MAG1-D) (Fig. 1). The PPU performs initial pulse conditioning and consists of a command resonant charge section (CRC) and deQ components for pulse amplitude regulation [5,6]. An intermediate energy storage section (IES), the last commandtriggered switch prior to the magnetic modulator, follows the

\footnotetext{
*Performed jointly under the auspices of the US DOE by LLNL under W-7405-ENG-48 and for the DOD under SDIO/SDC MIPR No. W43-GBL-0-5007.
}

CRC. The CRC and deQ sections utilize two parallel English Electric Valve thyratrons (EEV 1826) per section because of current ratings. Four parallel thyratrons (EEV 1547) are used in the IES to minimize jitter.

High PRF operation of a thyratron required preventing immediate re-application of a reverse voltage across the tube. Ferrite diodes in both the CRC and IES loops served this purpose (Fig. 1). In the IES loop, a bias circuit is used to maintain the core in the forward saturated state. The magnetic modulator (MAG1-D) performs the final pulse conditioning prior to the induction cell [7]. This final pulse conditioning is performed with three stages of saturable magnetic cores and capacitors in a "pi" type ladder configuration, i. e. a Melville line [8]. A transformer is used in the first stage to provide a voltage gain of about 10 .

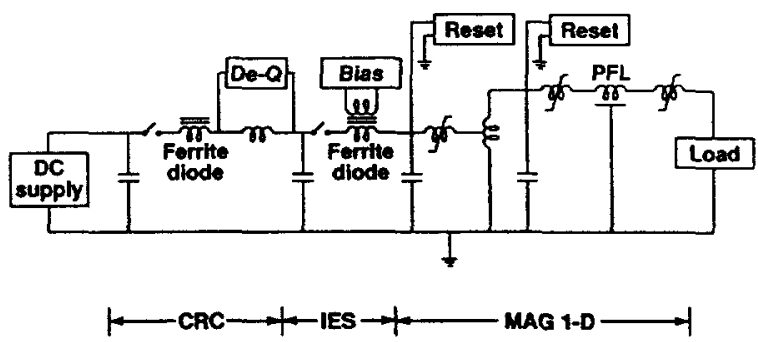

Fig. 1. HAPTS power conditioning chain.

A charge transfer time of $4 \mu \mathrm{s}$ is required from the PPU to the MAG1-D; an output pulse of 70 ns (FWHM) with a 15 ns rise time is produced at the MAG1-D output. Overall efficiency of the MAG1-D is about 70\% energy transfer into a linear load at full voltage. Typical energy output during a 50 pulse burst is on the order of $25 \mathrm{~kJ}$.

The HAPTS development program has focused on minimizing random shot-to-shot and burst-to-burst pulse amplitude and timing variation. Minimizing these quantities assures reproducible beam transport and preservation of beam qualities throughout a pulse burst.

Proper beam transport and preservation of beam quality in an LIA requires minimum energy sweep over the pulse duration [9]. In a practical system, because of accelerator cell non-linearities and a non-zero pulse rise-time, the usable pulse width is somewhat less than the full pulse duration. This usable pulse duration is determined by the operating point of the accelerator which includes beam current, accelerator gap voltage, and beam to voltage pulse timing. Thus, to ensure reproducibility, either an operating point with a broad maximum must be chosen (i. e. a robust, low sensitivity operating point) [10], or stringent requirements must be placed on reproducibility of the pulse shape at the accelerator cell.

Prior to fielding the ETA-II 60 cell experiment, we began a development effort upgrading and characterizing the power 
conditioning chain on HAPTS for eventual implementation on ETA-II. The upgrades stabilized system performance; characterizing the system allowed us to determine the most suitable operating point. We describe the progress to date here.

\section{Jitter and Regulation Measurements}

\section{A. System Upgrades}

Measurements on the ETA-II power conditioning chain prior to our most recent upgrades were reported earlier [11]. These past measurements indicated large voltage variations at an intermediate stage within the MAG1-D at increased PRF. Inadequate bias and reset circuit damping was understood to be the cause of these oscillations.

From these previous and additional studies, we implemented changes to both the bias and reset circuitry. These initial improvements consisted of separate IES bias and pre-compression (1st modulator stage) reset circuits. The topology of the MAG1-D reset circuits was also reconfigured and damped to allow stable reset of the saturable magnetics.

The Melville line is sensitive to input voltage fluctuations. Pulse-to-pulse stability of the MAG1-D output required a stable pulsed input voltage source, i. e. PPU output regulation. Thus, in addition to the reset and bias changes, we improved PPU regulation by implementing improved control circuitry [6]. This additional circuitry allowed for the additional delay in the ferrite diode in the CRC circuit. Typical regulation of the PPU at high PRF was measured to be on the order of $0.5 \%$.

\section{B. Jitter Measurements}

For the purpose of this paper, we define jitter as random deviation about some systematic variation in timing. Systematic variation is easily corrected by external compensation [see for example 5]; random deviation directly impacts the accelerator operation. In this paper, one sigma variation is quoted in each quantity.
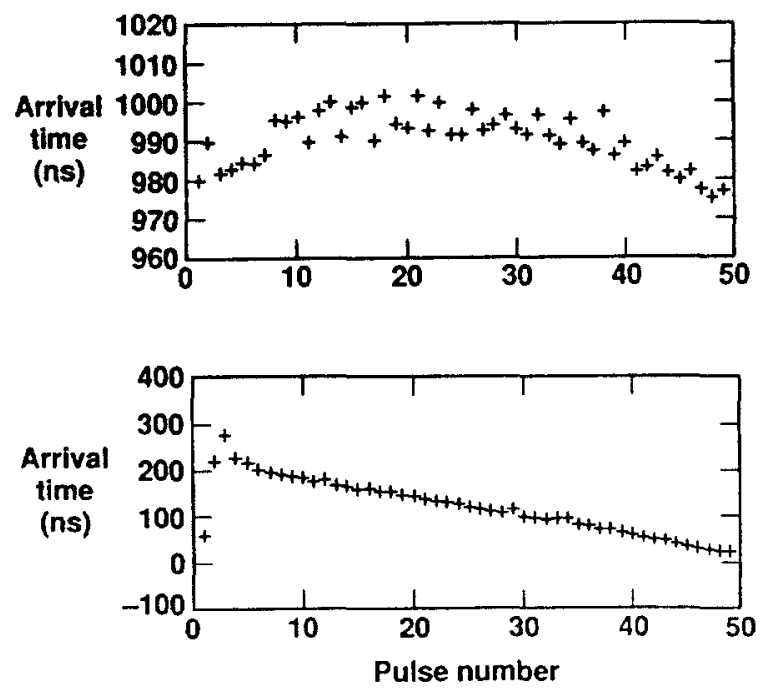

Fig. 2. MAG1-D output timing signature at: $1 \mathrm{kHz}$ (top) and $5 \mathrm{kHz}$ (bottom).
Typical MAG1-D output timing signatures measured at 1 and $5 \mathrm{kHz}$ are shown in Figure 2. In each case, PPU jitter varied from about $6 \mathrm{~ns}$ at $1 \mathrm{kHz}$ PRF to about $9 \mathrm{~ns}$ at $5 \mathrm{kHz}$ PRF. Output voltage was approximately $95 \mathrm{kV}$ into a linear load.

At $1 \mathrm{kHz}$, about $3 \mathrm{~ns}$ of random jitter accompanied a systematic variation of about $7 \mathrm{~ns}$. At an increased PRF of 5 $\mathbf{k H z}$, a random variation of approximately $5 \mathrm{~ns}$ accompanied a systematic variation of 75 ns. For a PRF between 1 and 5 $\mathrm{kHz}$, the systematic variation reached a maximum of 200 ns with a more complex signature appearing at a PRF of $4 \mathrm{kHz}$.

Reproducibility of the timing signature was measured over long operational periods. An example of the reproducibility of the timing signature at $5 \mathrm{kHz}$ PRF is shown in Fig. 3. Drift of the slope of a straight line fit to the timing of the last 45 pulses in a 50 pulse burst show good reproducibility over a 300,000 pulse test. For this test, the slope remains constant at $4.5+/-0.3 \mathrm{~ns} /$ pulse. The random jitter component remained at about $5 \mathrm{~ns}$.

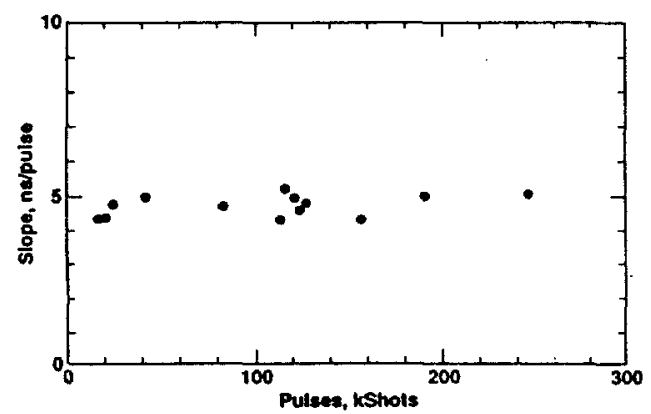

Fig. 3. Typical timing signature variation at $5 \mathrm{kHz}$ PRF 50 pulse burst.

Timing variation and jitter measurements at $5 \mathrm{kHz}$ were made under different cell loading conditions. Both of these quantities were found to be independent of load impedance from 2.0 (matched) to $2.7 \mathrm{ohm}$.

Growth of the timing variation and jitter was measured through the system. Jitter originated in the IES section and changed gradually through the system. Systematic variation, however, appeared to originate at the precompression or transformer stage of the MAG1-D.

\section{MAG1-D Output Voltage Regulation}

The output regulation characteristics of the MAG1-D were determined at several voltages, pulse repetition frequencies and load conditions. With an exception at $4 \mathrm{kHz}$, the average grouping in the output regulation was about $0.7 \%$ (one sigma pulse amplitude variation divided by the mean). Measurement resolution was 8 bit. A large variation in regulation accompanied the large timing variations at $4 \mathrm{kHz}$ as mentioned in the previous section. Again, output voltage was about 95 $\mathrm{kV}$ into a linear load.

A 50 pulse overlay and regulation measurement taken during a typical $5 \mathrm{kHz}, 50$ pulse burst at approximately 95 $\mathrm{kV}$, is shown in Fig. 4. Timing variation and jitter is not shown for clarity. The first plot shows that the reproducibility of the pulse shape during the burst was excellent. 
Variation in pulse amplitude is shown in the accompanying plot. Regulation during this particular burst was $0.71 \%$ and appears to be on the order of instrument resolution.

Additional regulation measurements at $5 \mathrm{kHz}$ were made under different cell loading conditions. Voltage regulation at the MAG1-D was measured to be independent of load impedance which varried from 2.0 (matched) to $2.7 \mathrm{ohm}$.

Regulation was measured at 1 and $5 \mathrm{kHz}$ as a function of MAG1-D output voltage. At $1 \mathrm{kHz}$, regulation was measured to be below $0.7 \%$ for MAG1-D output voltages exceeding 110 $\mathrm{kV}$. At $5 \mathrm{kHz}$, however, regulation increased to $20 \%$ above about $100 \mathrm{kV}$.
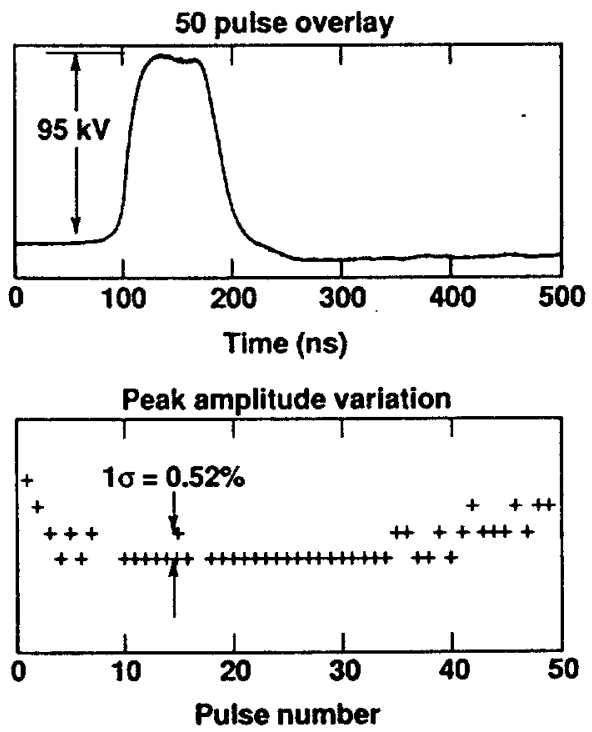

Fig. 4. Typical $5 \mathrm{kHz}$ regulation results.

\section{Summary}

We have measured the characteristics of the ETA-II power conditioning chain to $5 \mathrm{kHz}$ after implementing preliminary system changes, i. e., improved reset and bias circuits and improved PPU regulation. With these changes, we found that system performance improved significantly. Timing variation ranged from about $7 \mathrm{~ns}$ at $1 \mathrm{kHz}$ to a maximum of $200 \mathrm{~ns}$ at 4 $\mathrm{kHz}$. At 1 and $5 \mathrm{kHz}$, random jitter was measured to be 3 to 5 ns about a reproducible variation. Pulse-to-pulse voltage regulation was measured to be approximately $0.7 \%$. This regulation level was maintained at $1 \mathrm{kHz}$ to greater than 110 $\mathrm{kV}$ MAG1-D output voltage and at $5 \mathrm{kHz}$ to approximately 95 $\mathrm{kV}$.

Additional improvements are presently being studied and implemented. Our measurements indicate that the precompression stage of the MAG1-D is responsible for the majority of the timing variation and also for the inadequate regulation at elevated MAG1-D output voltages. We are pursuing the addition of core material to that stage, additional stabilization of the reset circuit, and active control of core reset. To stabilize the present system further, we are also considering timing compensation as a means to remove systematic timing variation.

\section{References}

1. R. J. Briggs, D. L. Birx, D. S. Prono, D. Proznitz, and L. L. Reginato, "Induction Linac Based FELs," in Proceedings of the IEEE Particle Accelerator Conference, Washington D. C., pp. 178-182, 1987.

2. L. L. Reginato, "The Advanced Test Accelerator (ATA) a $50 \mathrm{MeV}, 10 \mathrm{kA}$ Induction Linac," presented at the 1983 Particle Accelerator Conference, Santa Fe, NM, March 1983.

3. W. A. Barletta, "Accelerating Intense Electron Beam," in Energy and Technology Review, Lawrence Livermore National Laboratory, Livermore, CA, UCRL-52000-79, September 1979.

4. S. Humphries, Principles of Charged Particle Acceleration, John Wiley and Sons, New York, 1986.

5. M. A. Newton and J. A. Watson, "Timing and Voltage Control of Magnetic Modulators on ETA-II," presented at the 7th IEEE Pulsed Power Conference, Monterey, CA, June 1989, pp. 175-177.

6. J. A. Watson, A. N. Payne, S. E. Sampayan, and C. W. Ollis, "Precision Voltage Regulation on the $5 \mathrm{kHz}, 3.125$ MW ETA-II Pulse Power System," to be presented at the 8th IEEE Pulsed Power Conference, San Diego, CA, June 1991.

7. W. C. Turner, D. M. Barrett, and S. E. Sampayan, "Critical System Issues and Modeling Requirements -the problem of Beam Energy Sweep in an Electron Linear Accelerator," presented at the Intemational Magnetic Pulse Compression Workshop, Lake Tahoe, CA, February 1990.

8. W. S. Melville, "The Use of Saturable Reactors as Discharge Devices," IEE Proceedings (London), Part 3: Radio and Communication, vol. 98, pp. 185, 1951.

9. Y-J. Chen, "Corkscrew Modes in Linear Accelerators," Nucl. Instrum. and Meth. in Physics Research, A292, pp. 455-464 (1990).

10. S. E. Sampayan, G. J. Caporaso, Y-J. Chen, T. A. Decker, and W. C. Turner, "Energy Sweep Compensation of Induction Accelerators," presented at the 1990 Linear Accelerator Conference, Albuquerque, NM, September 1990.

11. M. A. Newton, D. M. Barrett, C. W. Ollis, and D. L. Pendleton, "Energy Flow and High Repetition Rate Issues for the ETA-II Magnetic Modulator System, " presented at the 1990 Linear Accelerator Conference, Albuquerque, NM, September 1990. 


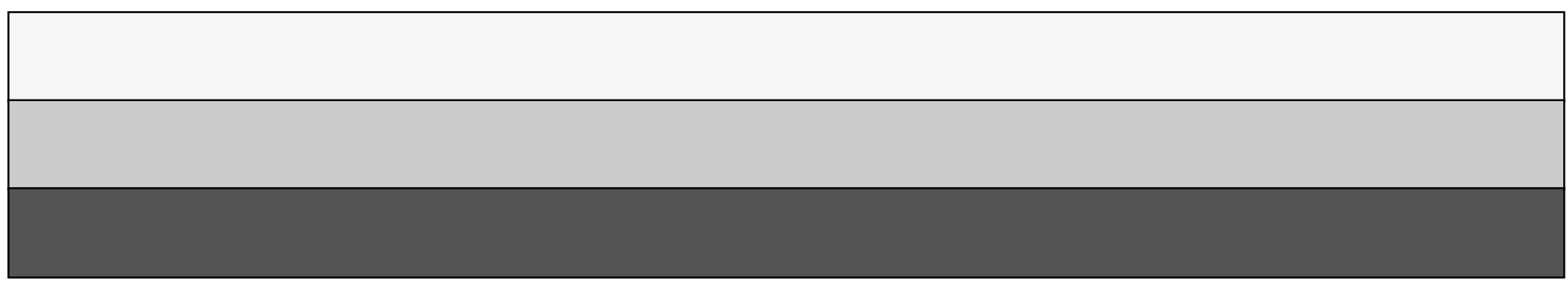

